\title{
Washable Stitched Transmission Line for Wearable Applications
}

\author{
Isaac H Daniel ${ }^{1}$, Ibrahim Umar², Nicodemus Kure ${ }^{1}$ and Abdullahi A Kassimu \\ ${ }^{1}$ Department of Physics, Kaduna State University, Kaduna, Kaduna State, Nigeria \\ 2 Department of Physics, Nassarawa State University, Lafiya, Nassarawa State, Nigeria \\ ${ }^{3}$ National Institute for Policy and Strategic Studies, Kuru, Nigeria \\ Corresponding E-mail: isaac.daniel@kasu.edu.ng
}

Received 27-05-2021

Accepted for publication 17-12-2021

Published 22-12-2021

\begin{abstract}
In this paper the washability of a stitched transmission line is been studied. The aim is to determine the deterioration of the frequency dependence of the scattering parameters of the stitched transmission line after subjecting it to washing cycles using a domestic washing machine. The DC resistance of the stitched transmission line was measured before and after wash with results indicating an increase in the DC resistance from $16.9 \Omega$ to $22.8 \Omega$ after washing the stitched transmission line. The increase in DC resistance is due to the decrease in conductive path of the stitched transmission line as a result of the abrasion impacts in the washing machine leading to increased number of fissures and defects on the stitched transmission line. The propagation characteristics of the stitched transmission line were investigated using CST Microwave Studio Suite ${ }^{\circledR}$ and measurements on the stitched transmission line before and after wash was carried out using an Anritsu $\mathrm{MS} 46524 \mathrm{~A} 7 \mathrm{GHz}$ Network Analyser for a frequency range of 0.04 to $4 \mathrm{GHz}$, with results demonstrating that the stitched transmission line will make a good candidate for wearable applications.
\end{abstract}

Keywords: Washability; Washing cycles; Stitched transmission line; Conductive threads; Scattering parameters; Wearability; DC resistance and Scattering Electron Microscope

\section{INTRODUCTION}

$\mathrm{W}$ ith the rapid growth and use of wearable devices over the last decade, the advantages of using portable wearable devices are now been utilized for day to day activities. These wearable devices are designed to be flexible, low profile, light-weight and smoothly integrated into daily life. Generally, for a wearable system to satisfy wearable requirements on robustness and ergonomics [1], the conductive textile is expected to display some wearable characteristics such as comfortability, durability, washability and flexibility.

Humans tend to have the urge to wash their apparels especially with the convenience of using washing machines even when they are not dirty; hence the washability of wearable devices comes into question.

The washability of wearable devices, which refers to the ability of a wearable device to be washed without causing any damage to the wearable device has always been an interesting topic, and with washability been an important aspect of wearability, one is always quick to ask about the washability of these wearable devices and their performance after been washed. However, it is worth mentioning here, that some wearable devices can withstand washing and drying provided the power source is detached or they are not being powered by some power source. While for some wearable devices, the temperature at which they are being washed is more of an issue than the washing process itself, as the 
temperatures these wearable devices can withstand vary form one device to the other.

Some approaches have been made to study the washability of wearable transmission lines. Chedid et al. in [1] presented an experimental and modelling based study on the deterioration of per-unit-length parameters of conductive textile transmission line when subjected to washing cycles. In [2], the conductivity of a transmission line was tested to determine changes in its electrical conductivity after subjecting it to washing cycles with results indicating no significant difference after 10 washing cycles. Similar results to [2] were obtained in [3] for a nanowire-coated nylon thread, whose resistance remained relatively constant after five repeated washing in a liquid detergent. While in [4], the washability of conductive threads used in constructing traces and touch sensors in wearable electronic systems was also explored.

In [5], a stitched transmission line constructed using a sewing machine, with the aid of a novel presser foot was proposed for broadband operation using the idea of a braided coaxial cable. In this study, the washability of the stitched transmission line proposed in [5] is been explored. The aim here is to determine the deterioration of the frequency dependence of the stitched transmission line after subjecting it to washing cycles for a frequency range of 0.04 to $4 \mathrm{GHz}$.

\section{STITCHED TRANSMISSION LINE DESIGN AND FABRICATION}

When The stitched wearable transmission line was modelled as a composite counterwound helical structure with a concentric conductor as proposed by Wait [7]. The design was carried out with CST Microwave Studio Suite ${ }^{\circledR}$, with design dimensions chosen as that of RG174 braided coaxial cable.

To construct the stitched wearable transmission line, a $R G 174$ braided coaxial cable was stripped of its outer jacket and shield leaving behind the inner conductor and the tubular dielectric material made up of Polyethylene. The stripped transmission line was stitched on to a Denim material which serves as the substrate with the aid of a sewing machine (see Fig.1), while conductive threads from Light Stitches ${ }^{\circledR}$ were used as the shield. The substrate size is $150 \mathrm{~mm} \times 100 \mathrm{~mm}$, while the length of the stitched transmission line is $150 \mathrm{~mm}$.

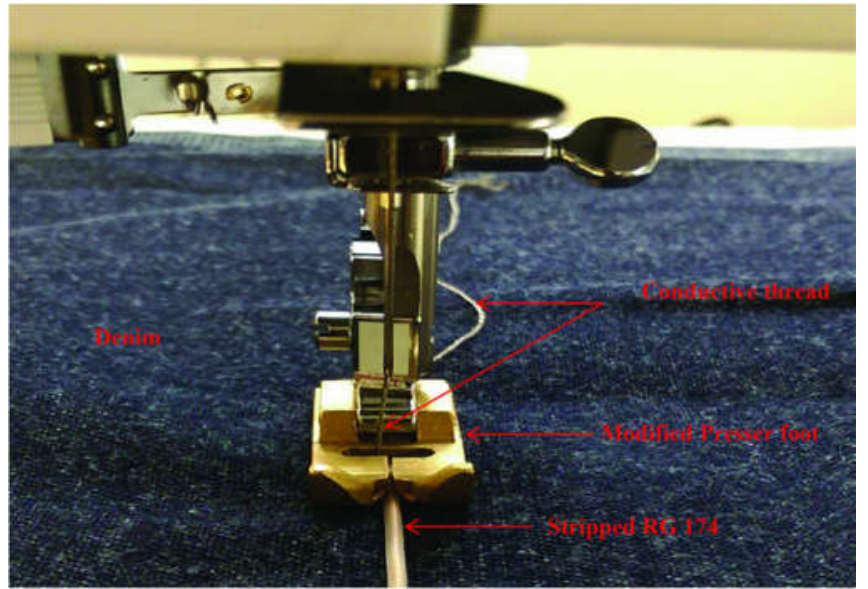

Fig. 1 Novel presser foot used with Singer Talent ${ }^{\circledR}$ sewing machine $[5,7]$.

Since the stripped RG174 transmission line is placed on the apparel prior to lowering the presser foot on both the stripped RG174 transmission line and the apparel while running the stitch, a novel presser foot was fabricated to meet this constraint without upsetting the tubular dielectric medium of the stripped transmission line. The fabricated stitched transmission line is shown in Fig. 2.

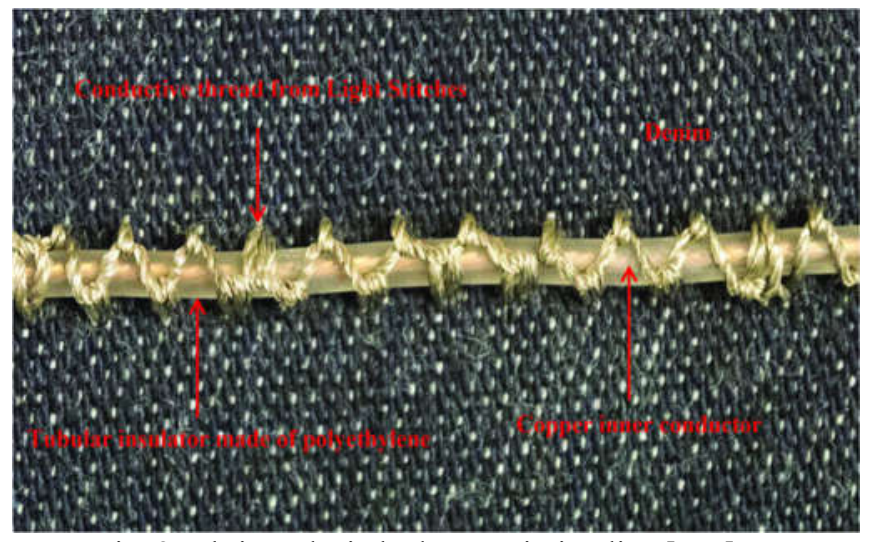

Fig. 2 Fabricated stitched transmission line $[5,7]$

\section{IMPACT OF WASHING}

The exposure to rain, sweat, oil, dust and dirt can affect the performance of a wearable device, consequently practical textiles now available in the market are designed to be heatresistant, antibacterial, oil-water repellent, impermeable, windproof with good breathability and moisture transport [8]. For the stitched transmission line to be used in smart textile applications, good washability properties are important. The domestic washing behavior of the stitched transmission line with tension at 4 , stitch length and width set at $2 \mathrm{~mm}$ respectively was evaluated after subjecting it to washing cycles using Bio Persil detergent washing powder in a Hotpoint washing machine. Two samples of the stitched transmission line were produced. While measurements were 
carried out on the first without being washed, the second was subjected to a standard $60^{\circ} \mathrm{C}$ cycle without connectors before measurements were made.

\section{A. DC resistance}

The DC Resistance of the stitched transmission line was measured for before and after washing. The DC resistance is seen to increase from $16.9 \Omega$ before washing to $22.8 \Omega$ after washing as shown in Table I.

Table I DC Resistance of the Stitched Transmission Line before and after Washing

\begin{tabular}{|l|l|l|l|l|l|l|l|}
\hline \multicolumn{2}{|l|}{ Stitched Transmission Line } & A & B & C & D & E \\
\hline $\begin{array}{l}\text { Stitch } \\
\text { Tension }\end{array}$ & $\begin{array}{l}\text { Stitch } \\
\text { Width } \\
(\mathrm{mm})\end{array}$ & $\begin{array}{l}\text { Stitch } \\
\text { Length } \\
(\mathrm{mm})\end{array}$ & $\begin{array}{l}\text { Machine } \\
\text { Wash }\end{array}$ & 60 & $\begin{array}{l}\text { Bio } \\
\text { Persil }\end{array}$ & 16.9 & 22.8 \\
\hline 4 & 2 & 2 & & & & \\
\hline
\end{tabular}

From Table I, A is washing type, B is washing temperature in ${ }^{\circ} \mathrm{C}, \mathrm{C}$ is detergent used, $\mathrm{D}$ is resistance before washing in $\Omega$ and $\mathrm{E}$ is the resistance after washing in $\Omega$.

The increase in DC resistance of the stitched transmission line was as anticipated because as temperature changes, the dimensions of the conductor will change as it expands or contracts. Although, these changes in resistance cannot therefore be explained by a change in dimensions due to thermal expansion or contraction, for a given size of conductor the change in resistance is mainly due to a change in the resistivity of the material, and this is caused by the changing activity of the atoms that make up the material. However, a much plausible reason for the increase in the resistance of the stitched transmission line after washing can be attributed to the loss of some metal fibers due to abrasion impacts in the washing machine, thus reducing the conductive path of the stitched transmission line.

\section{B. Visual Investigation of the Stitched Transmission Line}

Scattering electron microscope (SEM) images of the stitched transmission line were taken with the JEOL JSM-7800F FESEM, to visually investigate the condition of the conductive threads before and after washing. Prior to using the Scattering electron microscope, the two samples were sputter coated for 60 seconds with Gold palladium ( $\mathrm{Au} / \mathrm{Pd}$ ) using Quorum Q150R, which is a compact rotary-pumped coating system suitable for SEM sputtering with non-oxidizing (noble) metals and for carbon coating SEM specimen for EDS (Energydispersive X-ray spectroscopy) and WDS (wavelength dispersive X-ray spectroscopy) [9].

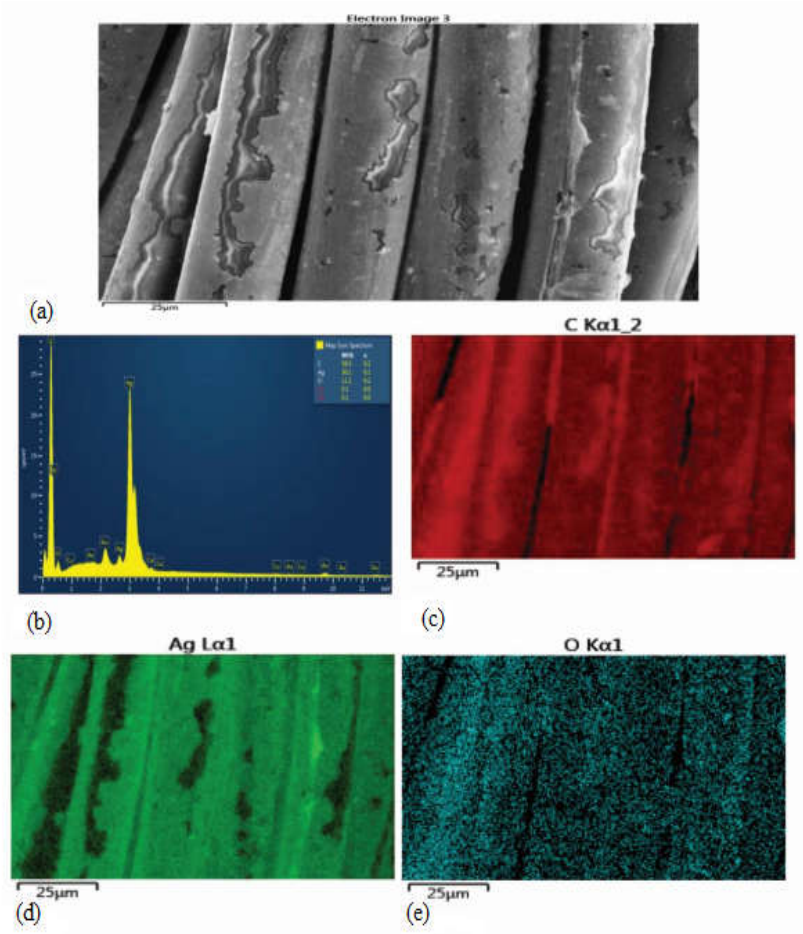

Fig. 3 Scanned image of unwashed stitched transmission line with (b) showing the composition of the elements, while (c)-

(e) colours depicting the presence of the elements.

Fig. 3 and 4 (a)-(e), shows the scanned images of the stitched transmission line, EDS map spectrum with images showing the average composition in weight \% (wt.\%) and the statistical error displayed as $\sigma$ (weight \% sigma) for the calculated weight and the X-ray element maps showing presence of carbon, silver and oxygen. Some fissures were also seen on the unwashed sample with an even distribution of silver on it. The unwashed sample also contains carbon, silver and oxygen with some trace of copper and calcium which are both below detection limits.

The silver in the washed sample is also seen to be evenly distributed. The fissures on the conductive thread appear to be more on the washed sample which shows the continuous silver coating to be more delaminated by washing. The washed sample also contains carbon and silver, with some trace amount of copper and calcium which all appear to have more average composition in weight $\%$ compared to the unwashed sample. 


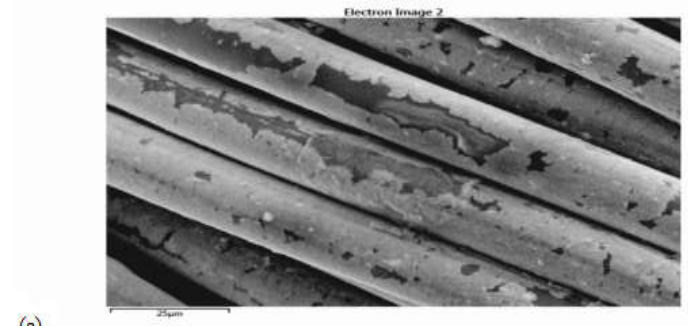

(a)
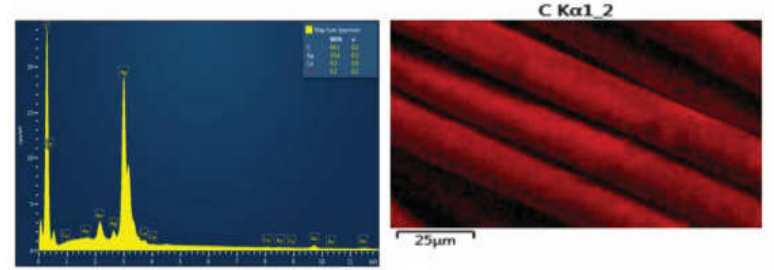

(b)

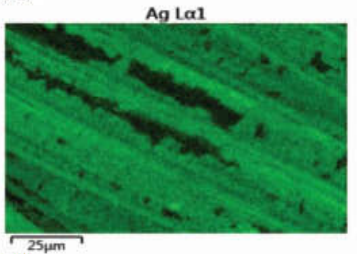

(d)

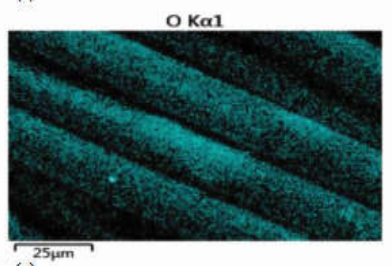

(e)

Fig. 4 Scanned image of washed stitched transmission line with (b) showing the composition of the elements, while (c)(e) colours depicting the presence of the elements.

\section{Transmission Characteristics}

The simulated and measured scattering parameters for a frequency range of 0.04 to $4 \mathrm{GHz}$ for the straight $150 \mathrm{~mm}$ long stitched transmission line is shown in Fig. 5.
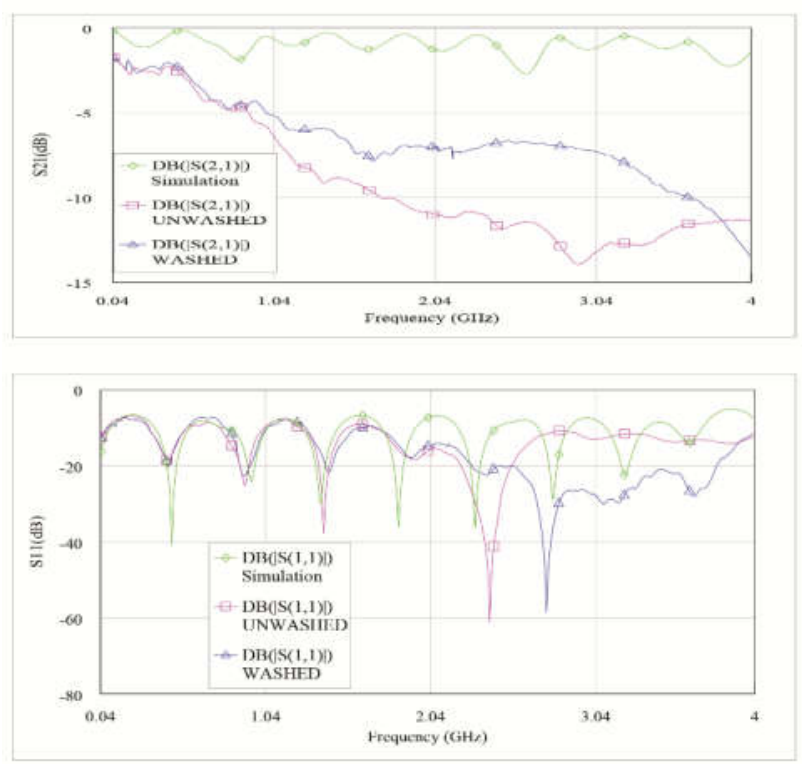

Fig. 5 Simulated and Measured S-Parameters of WASHED and UNWASHED stitched transmission line.

The measured reflection coefficients $S_{11}$ are below $-6.1 \mathrm{~dB}$ for frequencies up to $3.8 \mathrm{GHz}$ for the simulation results with CST Microwave Studio Suite ${ }^{\circ},-6.5 d B$ for the UNWASHED stitched transmission line and $-7.2 d B$ for the WASHED stitched transmission line in most of the operation band, while the transmission coefficients $S_{21}$ are better than $-1.9 \mathrm{~dB}$ for frequencies up to $2.49 \mathrm{GHz}$ for the simulation results with CST Microwave Studio Suite ${ }^{\circledR}$, and $-11.9 d B$ for frequencies up to $2.7 \mathrm{GHz}$ for the UNWASHED, and $-7.9 \mathrm{~dB}$ for frequencies up to $3.2 \mathrm{GHz}$ for the WASHED stitched transmission line respectively.

Interestingly, the scattering parameters look much better with the washed line, which is quite good for wearability applications. Two hypothesis are proposed here as to why this could be happening; first the washing off of the oil and dirt that sticks to the stitched transmission line during stitching. However, washing could also lead to the swelling of the thread when it absorbs water through pre-existing cracks and defects in the silver plaiting, causing an increase amount of cracks and defects.

Secondly, the slight change in the tension within the threads. Generally, textile materials have viscoelastic behavior [2], internal tensions relieve over time and the geometry may also change due to washing [6].

\section{CONCLUSIONS}

In this paper, the washability of a stitched transmission line proposed in [5] was put to test. The purpose here is to determine the deterioration of the frequency dependence of the scattering parameters after exposing the stitched transmission line to washing cycles for frequencies up to $4 \mathrm{GHz}$. The scattering parameter results for the washed stitched transmission line were seen to be better compared to the unwashed line. Two hypotheses were proposed to explain this improvement; first is the washing off of the oil and dirt that sticks to the stitched transmission line during fabrication and secondly, the slight change in tension within the thread during washing.

Furthermore, the DC resistance of the stitched transmission line was also measured before and after washing with measured results indicating an increase in the DC resistance of the stitched transmission line from $16.9 \Omega$ before washing to $22.8 \Omega$ after washing contrary to results presented in [1] and [10]. This change is largely attributed to the changing activity of the atoms that make up the conductive thread material and to the loss of some metal fibers due to abrasion impacts in the washing machine during the washing process.

\section{ACKNOWLEDGMENT}

The authors acknowledge the use of the facilities and assistance of Mr. Keith Yendall in the Loughborough Materials Characterizations Centre. 


\section{References}

[1] M. Chedid, I. Belov, and P. Leisner, "Experimental analysis and modelling of textile transmission line for wearable applications", Inter. Journ. of Cloth. Sc. and Tech., vol. 19, no. 1, pp. 59-71, 2007.

[2] V. Koncar, "Smart Textiles and Their Applications", Woodhead Publish. Series in Tex.: Series 178, pp. 67, 2016.

[3] Y. Atwa, N. Maheshwari, and I. A. Goldthorpe, "Silver nanowire coated threads for electrically conductive textiles", Journ. of Mat. Chem. C, 3, pp. 3908-3912, 2015.

[4] C. Zeagler, S. Gilliland, S. Audy, and T. Starner, "Can I wash it? The effect of washing conductive materials used in making textile based wearable electronic interfaces", In Proceed. of the 17th annual inter. Symp. on Inter. Symp. on wearable comp., pp. 143-144, 2013.

[5] I. H. Daniel, J. A. Flint, and R. Seager, "Stitched Transmission Lines for Wearable RF Devices", Microw. and Optic. Tech. Lett., vol. 59,no. 5, pp. 1048-1052, 2017.

[6] J. R. Wait, "Electromagnetic Theory of the Loosely Braided Coaxial Cable: Part I", IEEE Transactions on Microwave Theory and Techniques, vol. 24, no. 9, pp. 547-553, 1976.

[7] I. H. Daniel, N. Kure and A. A. Kassimu, "Two-way comparison between stitched transmission lines with copper wires and conductive threads, and with conductive threads only", J. Elect and Elect. Eng. Res., vol. 9, no. 1, September 2017.

[8] M. Joshi, and A. Bhattacharyya, "Nanotechnology a new route to high performance functional textiles", Tex. Prog., vol. 43, no. 3, pp. 155-233, 2011.

[9] Q150R $\AA$ May, 2021. [Online]. Available: (https://www.quorumtech.com/quorumproduct/q150r-rotary-pumped-sputter-coatercarboncoater)

[10]D. Cottet, J. Grzyb, T. Kirstein, and G. Tröster, "Electrical Characterization of Textile Transmission Lines", IEEE Trans. on Adv. Pack., vol. 26, no. 2, pp. 182-190, 2003. 